\title{
PERANAN EMOTIONAL INTELLIGENCE DAN SELF EFFICACY TERHADAP HARDINESS PADA PESERTA ORIENTASI PERSIAPAN KERJA
}

\author{
Sufarita $^{1}$, Riana Sahrani ${ }^{2}$, Rahmah Hastuti ${ }^{3}$ \\ ${ }^{1}$ Fakultas Psikologi, Universitas Tarumanagara Jakarta \\ Email: abdullah.sufarita@gmail.com \\ ${ }^{2}$ Fakultas Psikologi, Universitas Tarumanagara Jakarta \\ Email: riana1123@gmail.com \\ ${ }^{3}$ Fakultas Psikologi, Universitas Tarumanagara Jakarta \\ Email: rahmahh@fpsi.untar.ac.id
}

Masuk : 14-04-2019, revisi: 25-11-2019 diterima untuk diterbitkan : 26-11-2019

\begin{abstract}
ABSTRAK
Pada umumnya untuk memperoleh pekerjaan individu melalui rangkaian proses rekrutmen dan seleksi. Salah satu bagian dari rangkaian proses tersebut di Perusahaan X dilakukan orientasi persiapan kerja (OPK). Tahapan OPK ini dapat menjadi situasi yang penuh tekanan bagi para peserta. Untuk dapat berhasil menghadapi tekanan tersebut, individu harus memiliki hardiness yang tinggi. Dua hal yang dapat mempengaruhi hardiness individu adalah emotional intelligence dan self-efficacy. Penelitian ini bertujuan untuk mengetahui peranan emotional intelligence dan self-efficacy terhadap hardiness pada peserta OPK. Partisipan penelitian merupakan peserta OPK dengan karakteristik mengikuti proses seleksi reguler sebanyak 368 partisipan. Penelitian ini menggunakan metode kuantitatif dengan multiregression analysis. Hasil analisis data menunjukkan bahwa emotional intelligence dan selfefficacy secara bersama-sama berperan terhadap hardiness sebesar 25,9\% serta secara terpisah emotional intelligence berperan terhadap hardiness sebesar 22,2\% dan self-efficacy berperan terhadap hardiness sebesar 21,8\%. Berdasarkan penelitian ini disimpulkan bahwa emotional intelligence dan self-efficacy memiliki peranan terhadap hardiness pada peserta OPK.
\end{abstract}

Kata Kunci: emotional intelligence, self-efficacy, hardiness, orientasi persiapan kerja

\begin{abstract}
As part of job hiring, individuals must complete a series of recruitment and selection processes. One part of the process sequence is an employment preparation program (EPP). This stage of EPP can be a stressful situation for the participants. To be able to successfully deal with these pressures, individuals must have high hardiness. Two things that could affect individual hardiness are emotional intelligence and self-efficacy. This study aims to determine the contribution of emotional intelligence and self-efficacy on the hardiness of Participants of EPP. The research participants were participants in the EPP who are recruited by the regular selection process instead of a pro hire program or master's scholarship. This study uses a quantitative method with multi-regression analysis. The results of data analysis showed that emotional intelligence and self-efficacy had a role on hardiness, $(22,2 \%$ and $21,8 \%)$ respectively. It could be seen that emotional intelligence had a greater role on hardiness than self-efficacy of hardiness. Based on this study it was concluded that if emotional intelligence and self-efficacy of participants of EPP has a role on their hardiness.
\end{abstract}

Keywords: emotional intelligence, self-efficacy, hardiness, employment preparation program

\section{PENDAHULUAN}

\section{Latar Belakang}

Salah satu tugas perkembangan masa dewasa muda adalah menjadi mandiri secara finansial, sosial maupun psikologis (Santrock, 2002). Untuk menjadi mandiri secara finansial maka seseorang harus bekerja. Dengan demikian, masa dewasa awal dikatakan pula sebagai masa bekerja. Pada prosesnya untuk mendapatkan pekerjaan, terkadang seseorang harus melalui berbagai tahapan. 
Seperti yang dialami oleh calon karyawan Perusahaan X, tahapan seleksi yang harus dilalui oleh calon karyawan adalah tahap administrasi, tahap kompetensi, tahap kesehatan dan tahap orientasi persiapan kerja. Tahap orientasi persiapan kerja atau disingkat OPK meliputi kegiatan pendidikan pelatihan di kelas dengan lama kegiatan maksimal satu bulan, dan kegiatan job base di unit kerja atau on the job training (OJT) maksimal selama 12 bulan dengan evaluasi berkala. Pada tahun 2018 kegiatan OPK berlangsung selama 14 hari. Karena masih dalam tahap seleksi maka peserta yang tidak lulus akan gugur dan tidak dapat melanjutkan ke tahapan berikutnya. Persyaratan kelulusan OPK ini adalah mengikuti seluruh rangkaian kegiatan OPK dan memiliki nilai ujian tertulis minimal skor 65 .

Pada tahap OPK, peserta tidak hanya diberikan materi substansi perusahaan, tetapi juga diberikan materi soft skill serta latihan fisik dan mental. Latihan fisik dan mental tersebut melibatkan anggota marinir sebagai instrukturnya. Persyaratan kelulusan, metode pembelajaran dan rangkaian kegiatan OPK yang harus dijalani peserta ini disosialisasikan kepada peserta pada hari pertama mereka tiba di Learning Center Perusahaan $\mathrm{X}$ yang menjadi tempat penyelenggaraan OPK. Hal ini dilakukan dengan tujuan agar peserta mempunyai gambaran yang jelas atas hal-hal yang akan mereka hadapi selama dua minggu ke depan dan yang harus dipersiapkan untuk menjalaninya. Overview program OPK ini juga membuat peserta dapat memperkirakan sejauhmana kemampuan mereka untuk melaluinya serta kemampuannya tersebut dapat membuat mereka lulus pada tahapan OPK untuk maju ke tahapan selanjutnya yaitu OJT.

Padatnya jadwal kegiatan OPK dan latihan fisik yang dijalani memberi dampak tersendiri pada peserta OPK. Data evaluasi menunjukkan bahwa pada pelaksanaan OPK Gelombang II Tahun 2018, dari 120 peserta terdapat 74 peserta yang harus menjalani remedial ujian tertulis dan 27 peserta bahkan harus mengulang ujian untuk tiga sampai empat materi. Pada sesi coaching counselling bagi peserta yang menjalani remedial, salah seorang peserta yang bernama AA mengatakan bahwa dirinya merasa senang karena pada kegiatan ini banyak berkenalan dengan orang-orang baru, menjalani kegiatan bersama-sama, saling memberi dukungan jika ada peserta yang terlihat mengalami kesulitan. Di sisi lain, AA juga merasa tertekan menjalani kegiatan OPK terutama berkaitan dengan latihan fisik yang merupakan hal yang baru baginya. Ditambah lagi dengan jadwal kelas yang padat membuatnya semakin stres dan tidak siap saat menghadapi ujian (komunikasi personal, 30 September 2018).

Salah satu aspek kepribadian yang memengaruhi cara orang melihat dan berperilaku dalam situasi penuh tekanan adalah hardiness. Hardiness adalah konstruk psikologis yang merujuk pada keadaan individu dalam memberikan respon terhadap peristiwa tertentu dalam kehidupan (DiMatteo \& Martin, 2002). Individu yang memiliki hardiness mampu mengatasi tekanan dan masalah dengan cepat. Menurut Kobasa (1979) hardiness merupakan karakteristik kepribadian yang berfungsi sebagai sumber pertahanan ketika menghadapi peristiwa hidup yang menekan. Hardiness muncul sebagai seperangkat sikap atau kepercayaan mengenai diri dalam berinteraksi dengan dunia di sekitarnya (Maddi, 2002). Hardiness dicirikan dengan perilaku memberikan keberanian dan motivasi untuk melakukan kerja keras demi mengubah situasi stres menjadi peluang (Maddi, 2002).

Hal yang terjadi pada peserta OPK, dalam kondisi penuh tekanan tersebut peserta OPK masih tetap menunjukkan semangat untuk mengikuti kegiatan secara keseluruhan namun di lain sisi peserta juga mengalami keluhan fisik seperti sakit kepala, demam dan alergi. Pelatih Latihan Kedisplinan, Bapak RMBS mengatakan bahwa peserta OPK harus mampu mengelola emosi, terutama bagi peserta yang telah bekerja sebelumnya. Hal ini dikarenakan peserta harus 
menerima ketika diperintah untuk latihan fisik seperti berguling, berjalan jongkok dan latihan fisik lainnya. Ketika melakukan kesalahan peserta juga harus siap dibentak dan diberi hukuman (komunikasi personal, 10 September 2018).

Individu yang memiliki hardiness yang rendah akan merespon situasi penuh tekanan dengan emosi yang negatif, seperti marah, merasakan kecemasan dan depresi. Sedangkan, individu yang memiliki hardiness yang tinggi akan merespon situasi yang penuh tekanan dengan berani, tetap terlibat dengan lingkungan dan mencari cara untuk mengatasi situasi tersebut (Maddi, 2006).

Kemampuan yang baik dalam mengelola emosi disebut emotional intelligence. Emotional intelligence didefinisikan sebagai kemampuan untuk memahami emosi dalam rangka menilai pikiran, perilaku dan menempatkannya dengan cara tertentu yang membuat emosi dan intelektual berkembang (Goleman, 1995). Menurut Goleman (1995), emotional intelligence dua kali lebih penting dibandingkan intelligence quotient atau kecerdasan individu. Hal ini sejalan dengan konsep emotional intelligence menurut Bar-On (2000) yaitu kemampuan untuk mengenali dan membedakan perasaan, kegembiraan, makna dan konsep, serta hubungan diantaranya untuk mengatasi masalah. Kecerdasan emosi dianggap berhubungan dengan peningkatan kesehatan mental dan fisik di bawah tekanan (Tapia, 2001).

Individu dengan emotional intelligence yang tinggi akan lebih baik dalam mengatasi tuntutan emosi dalam situasi penuh tekanan karena mereka mampu untuk merasakan dan mengenali emosinya secara akurat, mengetahui waktu dan cara yang tepat untuk mengekspresikan perasaannya dan dapat mengatur kondisi suasana hatinya secara efektif (Salovey, Bedell, Detweiler \& Mayer, 1999). Sedangkan, individu dengan emotional intelligence yang rendah akan memperlihatkan reaksi yang emosional, toleransi yang rendah terhadap frustrasi, kurang mampu menyelesaikan masalah dan tidak mampu menerima kritik (Goleman, 2002). Kaitannya dengan hardiness, penelitian yang dilakukan oleh Dogaheh, Khaledian dan Arya (2013) mengenai hubungan antara psychological hardiness, emotional intelligence dan workaholism menunjukkan adanya hubungan yang positif antara emotional intelligence dan hardiness.

Faktor lain yang memengaruhi seseorang dalam menghadapi tekanan adalah self-efficacy. Menurut Bandura (1997), self-efficacy adalah kepercayaan seseorang akan kemampuannya dalam menghadapi tugas yang sulit. Bandura (1997) mengungkapkan bahwa individu yang memiliki self-efficacy yang tinggi akan mencapai suatu kinerja yang lebih baik karena individu ini memiliki motivasi yang kuat, tujuan yang jelas, emosi yang stabil dan kemampuannya untuk memberikan kinerja atas aktivitas atau perilaku dengan sukses. Berbeda dengan individu yang memiliki self-efficacy rendah, individu tersebut akan cenderung tidak mau berusaha dan menjauhi tugas-tugas yang sulit karena tugas tersebut dianggap sebagai ancaman.

Jackson dan Scheiner (2005) menyebutkan bahwa seseorang tidak akan dapat merespon tantangan, tidak akan menjadi sosok yang hardy tanpa memiliki keyakinan bahwa seseorang dapat menghasilkan suatu hasil sesuai yang diinginkan atau self-efficacy. Penelitian yang dilakukan oleh Iovu, Runcan dan Runcan (2015) menyatakan bahwa self-efficacy berhubungan dengan usaha yang dilakukan individu dan usaha yang dilakukan individu tersebut juga memberi pengaruh terhadap pencapaian individu dalam hal akademik.

Penelitian lain juga menunjukkan adanya korelasi positif antara hardiness dan self-efficacy. Shekarey, et al. (2010) meneliti mengenai self-efficacy dan hardiness serta keterkaitannya dengan perkembangan pendidikan pada siswa tahun kedua, hasilnya menunjukkan adanya 
hubungan yang positif antara hardiness dan self-efficacy. Semakin tinggi self-efficacy maka semakin tinggi pula hardiness yang dimiliki individu.

Fenomena yang terjadi pada peserta OPK adalah peserta mengalami dua hal yang berbeda. Satu hal peserta merasa senang karena mendapatkan pengalaman baru, berkenalan dengan orangorang baru, saling menyemangati dan mendukung jika ada peserta yang mengalami kesulitan. Dengan kata lain, peserta memiliki emotional intelligence yang cukup, namun di sisi lain masih banyak peserta yang menunjukkan gejala stres yang membuat peserta merasa takut akan kegagalan, merasa tidak berdaya akan situasi yang dihadapi yang berakibat pada penurunan kondisi fisik dan nilai ujian yang masih di bawah standar.

\section{Rumusan Masalah}

Berdasarkan latar belakang permasalahan, maka rumusan masalah pada penelitian ini adalah (a) Apakah emotional intelligence dan self-efficacy memiliki peranan terhadap hardiness pada peserta OPK? (b) Apakah ada peranan emotional intelligence terhadap hardiness pada peserta OPK? (c) Apakah ada peranan self-efficacy terhadap hardiness pada peserta OPK?

Sedangkan hipotesis dalam penelitian ini adalah (a) emotional intelligence dan self-efficacy secara bersama-sama memiliki peranan terhadap hardiness, (b) emotional intelligence memiliki peranan terhadap hardiness dan (c) self-efficacy memiliki peranan terhadap hardiness.

\section{METODE PENELITIAN}

\section{Partisipan}

Partisipan pada penelitian ini adalah calon karyawan Perusahaan $\mathrm{X}$ yang sedang menjalani Orientasi Persiapan Kerja (OPK) sebagai bagian dari proses seleksi penerimaan karyawan baru. Usia subyek adalah 24-27 tahun. Partisipan dalam penelitian ini tidak dibatasi dengan jenis kelamin, etnis, agama dan status sosial.

\section{Teknik Pengambilan Sample}

Populasi pada penelitian ini adalah seluruh peserta OPK sebanyak 483 orang. Terdapat 15 orang tidak memenuhi syarat untuk menjadi partisipan penelitian karena tidak melalui tahapan rekrutmen secara reguler, melainkan dari jalur khusus seperti professional hire dan penerima beasiswa S2. Penelitian ini menggunakan nonprobability sampling. Jenis pengambilan sampel yang digunakan adalah purposive sampling, yaitu teknik pengambilan sampel dengan pertimbangan tertentu sesuai dengan persyaratan sampel dan tinjauan penelitian.

\section{Desain Penelitian}

Penelitian ini dilakukan pada peserta orientasi persiapan kerja di Perusahaan X yaitu perusahaan yang berbentuk badan hukum publik. Pengambilan data dilakukan pada bulan November 2018 .

\section{Definisi Konseptual Variabel}

Definisi konseptual hardiness adalah karakteristik kepribadian yang berfungsi sebagai sumber pertahanan ketika menghadapi peristiwa hidup yang menekan dengan cara memiliki keyakinan akan control diri terhadap situasi, terlibat sepenuhnya dalam aktivitas kehidupannya dan situasi yang dihadapi dipahami sebagai suatu tantangan untuk pengembangan diri yang lebih baik.

Dimensi yang pertama adalah commitment. Dimensi ini menggambarkan tingkat keterlibatan individu dalam setiap kejadian dalam hidup serta menggambarkan keyakinan yang dimiliki individu akan tujuan hidupnya. Keyakinan tersebut membuat individu melibatkan diri pada setiap kegiatan atau kejadian dalam hidupnya. Pada dimensi commitment ini, semakin tinggi skor maka partisipan penelitian semakin terlibat pada kegiatan yang dijalaninya dan percaya akan tujuan hidupnya. Contoh butir positif dalam dimensi ini adalah: "Dengan bekerja keras, kita 
dapat selalu mencapai tujuan kita" dan contoh butir negatif adalah: "Bekerja keras tidak penting karena hanya atasan yang mendapatkan untung". Pada pengujian reliabilitas, nilai koefisien internal consistency pada dimensi ini adalah 0,788 . Seluruh butir pada dimensi ini memiliki nilai corrected item total correlation di atas 0,2 sehingga tidak dilakukan pembuangan butir. Instrumen penelitian yang digunakan adalah alat ukur hardiness yaitu Dispositional Resilience Scale (DRS) yang dikembangkan oleh Paul Bartone (Bartone, 1991).

Dimensi yang kedua adalah control. Dimensi ini menggambarkan kemampuan individu dalam mengatasi masalah dan tingkat keoptimisan individu dalam memandang hidupnya. Pada dimensi control, semakin tinggi skor menandakan partisipan penelitian mampu mengatasi masalah yang ada dan merasa optimis dalam memandang hidupnya. Seluruh butir pada dimensi ini adalah butir positif, contohnya "Ketika saya membuat rencana, saya yakin saya dapat mewujudkannya". Pada pengujian reliabilitas, nilai koefisien internal consistency pada dimensi ini adalah 0,743 . Seluruh butir pada dimensi ini memiliki nilai corrected item total correlation di atas 0,2 sehingga tidak dilakukan pembuangan butir.

Dimensi selanjutnya adalah challenge. Dimensi ini menggambarkan cara individu memandang perubahan sebagai hal positif. Maka pada dimensi challenge, semakin tinggi skor menggambarkan bahwa partisipan penelitian tidak takut dalam menghadapi perubahan. Contoh butir positif dalam dimensi ini adalah: "Saya menikmati tantangan ketika saya harus melakukan lebih dari satu hal secara bersamaan" dan contoh butir negatif adalah: "Saya merasa terganggu jika rutinitas harian saya mengalami perubahan". Pada pengujian reliabilitas, nilai koefisien internal consistency pada dimensi ini adalah 0,707 . Seluruh butir pada dimensi ini memiliki nilai corrected item total correlation di atas 0,2 sehingga tidak dilakukan pembuangan butir.

Definisi konseptual emotional intelligence adalah kapasitas atau kemampuan individu untuk memproses informasi emosional secara akurat dan efisien, meliputi informasi yang relevan dengan pengenalan, konstruksi dan pengaturan emosi pada diri sendiri dan orang lain. Alat ukur yang digunakan adalah Schutte Emotional Intelligence Scale (SEIS) yang disusun oleh Schutte et al. (1998) berdasarkan teori dari Salovey dan Mayer (1990). Awalnya alat ukur ini memiliki 62 butir dengan skala 1-5. Skala 1 berarti sangat tidak setuju dan skala 5 berarti sangat setuju. Selanjutnya alat ukur ini direvisi oleh Schutte et al. (1998) menjadi 33 butir, yang terdiri dari 13 butir merepresentasikan appraisal and expression of emotion, 10 butir merepresentasikan regulation of emotion dan 10 butir merepresentasikan utilization of emotion. SEIS memiliki internal consistency Alpha Cornbach sebesar 0,90 dan koefisien test-retest sebesar 0.78.

Dimensi appraisal and expression of emotion menggambarkan kemampuan individu dalam hal mengenali dan mengekspresikan emosi diri sendiri dan orang lain, baik itu secara verbal maupun nonverbal. Pada dimensi ini, semakin tinggi skor yang dicapai maka menggambarkan semakin tinggi kemampuan individu dalam mengenali dan mengekspresikan emosi. Contoh butir positif pada dimensi ini adalah: "Dengan melihat ekspresi orang lain, saya mengenali emosi yang dialami oleh orang tersebut" dan contoh butir negatif adalah: "Saya merasa kesulitan memahami bahasa tubuh secara nonverbal dari orang lain". Pada pengujian reliabilitas, nilai koefisien internal consistency pada dimensi ini adalah 0,838 . Seluruh butir pada dimensi ini memiliki nilai corrected item total correlation di atas 0,2 sehingga tidak dilakukan pembuangan butir.

Dimensi selanjutnya adalah regulation of emotion, yaitu kemampuan individu dalam mengelola emosi-emosi yang dirasakan untuk mencapai hasil yang diinginkan, dengan memahami implikasi diri dari tingkah laku sosial terhadap emosi dan pengelolaan emosi pada diri sendiri dan orang 
lain. Pada dimensi ini semakin tinggi skor yang diperoleh maka menggambarkan individu memiliki kemampuan yang semakin tinggi dalam mengelola emosinya. Tidak ada butir negatif pada dimensi ini dan contoh butir positif pada dimensi ini adalah: "Saya suka berbagi emosi saya dengan orang lain". Pada pengujian reliabilitas, nilai koefisien internal consistency pada dimensi ini adalah 0,823 . Seluruh butir pada dimensi ini memiliki nilai corrected item total correlation di atas 0,2 sehingga tidak dilakukan pembuangan butir.

Dimensi terakhir adalah utilization of emotion, yaitu kemampuan untuk mendatangkan, membangkitkan dan menggunakan emosi untuk memfasilitasi proses berpikir. Dengan kemampuan ini, individu akan mampu menyusun emosi-emosi untuk digunakan dalam mencapai suatu tujuan. Pada dimensi ini, semakin tinggi skor yang diperoleh maka menggambarkan kemampuan individu yang tinggi dalam menggunakan emosinya untuk membantu proses berpikir. Contoh butir positif pada dimensi ini adalah: "Ketika suasana hati saya sedang baik, memecahkan masalah menjadi mudah bagi saya" dan contoh butir negatif adalah: "Ketika saya menghadapi tantangan, saya menyerah karena tahu saya akan gagal". Pada pengujian reliabilitas, nilai koefisien internal consistency pada dimensi ini adalah 0,794 . Seluruh butir pada dimensi ini memiliki nilai corrected item total correlation di atas 0,2 sehingga tidak dilakukan pembuangan butir.

Definisi konseptual self-efficacy adalah keyakinan individu bahwa ia memiliki kemampuan untuk mengintegrasikan aspek kognitif, sosial dan perilaku menjadi sejumlah tindakan serta mengeksekusi tindakan-tindakan tersebut dengan baik pada berbagai situasi yang sulit (Bandura, 1997). Alat ukur yang digunakan adalah New General Self Efficacy Scale (NGSE) yang disusun oleh Chen et al. (2001). NGSE terdiri dari 8 butir dengan skala 1-5, yang bergerak dari sangat tidak setuju sampai dengan sangat setuju. Skor yang tinggi dalam pengukuran ini menandakan tingginya self-efficacy individu. Internal consistency dari alat ukur ini adalah antara 0,85 sampai dengan 0,90 dan koefisien test-retest antara 0,62 sampai dengan 0,65. Meskipun disusun dengan mengacu pada teori self-efficacy dari Bandura, tetapi NGSE ini merupakan alat ukur unidimensional. NGSE dinilai lebih efisien dan dapat memberikan hasil pengukuran self-efficacy yang akurat dengan jumlah butir yang lebih sedikit (Scherbaum et al., 2006).

Pada pengujian reliabilitas, nilai koefisien internal consistency pada dimensi ini adalah 0,874. Seluruh butir pada dimensi ini memiliki nilai corrected item total correlation di atas 0,2 sehingga tidak dilakukan pembuangan butir.

\section{HASIL DAN PEMBAHASAN}

Jumlah partisipan dalam penelitian ini sebanyak 368 orang yang terdiri dari 224 orang laki-laki dan 144 orang perempuan dengan rentang usia $24-27$ tahun. Terhadap partisipan dilakukan penggambaran data masing-masing variable. Setelah memperoleh gambaran tentang partisipan, maka selanjutnya dilakukan uji normalitas pada dependent variable dan analisa data utama berupa uji korelasi dan uji regresi.

Berikut adalah data mean hipotetik dan mean empiris masing-masing variable.

Tabel 1 Gambaran Data Variabel

\begin{tabular}{lccccc}
\hline & $\mathrm{N}$ & Minimum & Maximum & Mean & Std. Deviation \\
\hline Hardiness & 368 & 2.53 & 4.00 & 3.4229 & .33911 \\
Emotional Intelligence & 368 & 3.15 & 5.00 & 4.2901 & .35244 \\
Self-Efficacy & 368 & 3.13 & 5.00 & 4.2927 & .43320 \\
\hline
\end{tabular}




\section{Uji Normalitas Dependent Variabel}

Pengujian normalitas data diperlukan untuk menentukan teknik korelasi yang akan digunakan. Berdasarkan hasil uji Kolmogorov-Smirnov, didapatkan hasil bahwa variabel hardiness terdistribusi normal. Hal ini dikarenakan nilai $p$ pada pengujian Kolmogorov-Smirnov lebih besar dari 0,05 .

Tabel 2. Hasil Uji Normalitas Variabel Hardiness

\begin{tabular}{lccc}
\hline & \multicolumn{3}{c}{ Kolmogorov-Smirnov } \\
\cline { 2 - 4 } Variabel & Statistic & df & Sig. \\
\hline Hardiness & .019 & 368 & .055 \\
\hline
\end{tabular}

\section{Uji Korelasi}

Setelah melakukan uji asumsi, peneliti kemudian melakukan pengujian hubungan atau korelasi antara variabel emotional intelligence, self-efficacy dan hardiness. Pengujian dilakukan dengan menggunakan Pearson Correlation. Hasilnya, korelasi antara emotional intelligence dan hardiness adalah $\mathrm{r}=0,471$ dan nilai $p=0,000<0,05$. Dengan demikian, variabel emotional intelligence memiliki hubungan yang positif dengan hardiness. Artinya, semakin tinggi emotional intelligence maka semakin tinggi pula hardiness yang dimiliki individu.

Uji korelasi antara variabel self-efficacy dan hardiness juga menunjukkan hubungan yang positif. Hal ini ditunjukkan dengan hasil Pearson Correlation sebesar $\mathrm{r}=0,467$ dengan nilai $p=0,000<$ 0,05. Maka semakin tinggi self-efficacy, maka semakin tinggi pula hardiness yang dimiliki individu.

Hasil uji Pearson Correlation antara variabel emotional intelligence dan self-efficacy sebesar 0,693 dan nilai $p=0,000<0,05$, menunjukkan adanya hubungan yang positif antara kedua variabel. Semakin tinggi emotional intelligence, maka semakin tinggi self-efficacy individu.

\section{Uji Regresi}

Pada uji peranan variabel emotional intelligence dan variabel self-efficacy, didapatkan nilai $R$ Square sebesar 0,259. Hal ini menunjukkan bahwa variabel emotional intelligence dan variabel self-efficacy memiliki peranan terhadap variabel hardiness adalah sebesar $25,9 \%$, sedangkan sisanya dipengaruhi oleh faktor lain. Hal tersebut menunjukkan bahwa hipotesis penelitian dapat diterima, yaitu emotional intelligence dan self-efficacy memiliki peranan terhadap hardiness.

Tabel 3. Hasil Uji Regresi Variabel Emotional Intelligence dan Self Efficacy

\begin{tabular}{lrrrr}
\hline Model & R & R Square & $\begin{array}{c}\text { Adjusted R } \\
\text { Square }\end{array}$ & $\begin{array}{l}\text { Std. Error of } \\
\text { the Estimate }\end{array}$ \\
\hline 1 & .509 & .259 & .255 & .29271 \\
\hline
\end{tabular}

Selanjutnya peneliti menganalisis data untuk melihat ada atau tidak adanya peranan emotional intelligence dan self-efficacy terhadap hardiness. Didapatkan $\mathrm{F}=104,541$ dan 18,133 dengan tingkat signifikansi 0,000 menunjukkan bahwa secara keseluruhan baik variabel emotional intelligence dan self-efficacy memiliki peranan terhadap hardiness.

Untuk melihat besaran peranan emotional intelligence terhadap hardiness dan peranan selfefficacy terhadap hardiness, maka peneliti menggunakan analisis regresi sederhana. Pada perhitungan peranan emotional intelligence terhadap hardiness didapatkan nilai $R$ Square sebesar 0,222 menunjukkan bahwa peranan emotional intelligence terhadap hardiness sebesar 22,2\%. 
Penelitian sebelumnya yang dilakukan oleh Dogaheh et. al. (2013), bahwa terdapat hubungan yang signifikan antara emotional intelligence dan hardiness. Semakin tinggi skor emotional intelligence individu, maka semakin tinggi pula skor hardiness yang dimilikinya. Penelitian oleh Chan (dikutip dalam Byrne, 2012) juga menunjukkan adanya hubungan yang positif antara emotional intelligence dan hardiness.

Pada perhitungan peranan self-efficacy terhadap hardiness didapatkan nilai $R$ Square sebesar 0,218 menunjukkan bahwa peranan self-efficacy terhadap hardiness sebesar $21,8 \%$. Dengan demikian adanya self-efficacy dalam diri individu dapat menambah hardiness yang bersangkutan. Hal ini sejalan dengan pernyataan Kobasa (dikutip dalam Maddux \& Lewis, 1995), pada saat individu dapat melakukan kontrol pada situasi dan perilakunya, individu lebih mampu memenuhi tantangan hidup, menghadapi stres, membangun hubungan yang sehat dan mencapai kepuasan pribadi. Hal ini juga sejalan dengan penelitian yang dilakukan oleh Shekarey et al. (2010) yang dilakukan kepada mahasiswa di tahun kedua pendidikannya. Hasil penelitiannya menunjukkan bahwa ada hubungan langsung dan positif antara self-efficacy dan hardiness, dimana jika self-efficacy individu meningkat, maka hardiness individu juga meningkat.

\section{KESIMPULAN DAN SARAN}

Berdasarkan analisis data yang telah dilakukan mengenai peranan emotional intelligence dan self-efficacy terhadap hardiness pada peserta Orientasi Persiapan Kerja (OPK) maka diperoleh hasil bahwa terdapat peranan emotional intelligence dan self-efficacy secara bersama-sama terhadap hardiness sebesar $25,9 \%$. Adapun secara terpisah, peranan variabel emotional intelligence terhadap hardiness adalah sebesar $22,2 \%$ dan peranan variabel self-efficacy terhadap hardiness $21,8 \%$.

Diharapkan penelitian ini dapat menambah referensi bagi penelitian selanjutnya. Saran untuk penelitian selanjutnya adalah penelitian dapat dikembangkan dengan melakukan variasi metode penelitian, misalnya melakukan mixed method. Pengembangan penelitian juga dapat dilakukan dengan menggabungkan dua atau lebih metode riset seperti wawancara yang lebih mendalam, observasi ataupun dengan melakukan eksperimen. Dengan demikian dapat dilakukan pemeriksaan silang antara perilaku yang ditampilkan dan hasil kuesioner. Penelitian ini juga dapat dilanjutkan dengan mengukur hardiness peserta OPK setelah menjadi karyawan tetap, sehingga terlihat konsistensi dari hardiness yang dimiliki partisipan. Hasil dari penelitian lanjutan ini dapat menjadi bahan pertimbangan dalam menentukan persyaratan yang harus dipenuhi oleh calon karyawan.

Penelitian selanjutnya juga dapat memperluas ruang lingkup penelitian. Terkait jumlah partisipan penelitian yang dapat diperbesar dan diperluas dari berbagai instansi atau lembaga sehingga hasilnya lebih dapat dilakukan generalisasi. Selain itu penelitian dapat menggunakan alat ukur yang lebih spesifik dan lebih sesuai dengan kondisi penelitian.

Saran yang dapat diberikan peserta OPK dan peserta pelatihan pada umumnya agar dapat menjaga dan meningkatkan emotional intelligence dan self-efficacy yang dimilikinya sehingga hardiness dalam diri peserta juga meningkat. Selain itu, peserta pelatihan juga agar dapat secara aktif mencari program pelatihan yang berguna untuk peningkatan hardiness. Kepada peserta pelatihan dapat diberikan apresiasi jika berhasil menyelesaikan suatu tugas. Peserta yang belum berhasil diberikan bimbingan dan feedback. 
Saran yang dapat diberikan kepada perancang desain pelatihan dan para praktisi pendidikan untuk merancang pelatihan yang spesifik mengenai emotional intelligence, self-efficacy dan hardiness untuk mempersiapkan peserta didik dalam menghadapi situasi-situasi yang sulit dan penuh tekanan. Perancang desain pelatihan dapat menyusun modul untuk dilakukannya psikoedukasi tentang emotional intelligence, self-efficacy dan hardiness yang dapat diberikan baik kepada peserta pelatihan maupun kepada karyawan pada umumnya.

Perancang desain pelatihan juga dapat mengalokasikan waktu khusus untuk pemberian feedback kepada peserta pelatihan dalam bentuk coaching clinic. Feedback ini dimaksudkan untuk memberikan penguatan mengenai hal-hal yang positif dari individu dan memberikan gambaran hal-hal yang harus dilakukan peserta untuk mengatasi kekurangannya.

Kepada manajemen agar dapat dilakukan penelitian lebih lanjut terhadap aspek-aspek emotional intelligence, self-efficacy dan hardiness kepada karyawan. Dengan demikian, berkaitan dengan rekrutmen, dapat diketahui pentingnya dilakukan pengukuran terlebih dahulu kepada calon peserta OPK. Pengukuran dimaksud adalah pengukuran emotional intelligence, self-efficacy dan hardiness. Hal ini memiliki keterkaitan terhadap kesuksesan karyawan dalam menyelesaikan tugas-tugasnya, baik sebagai peserta pelatihan maupun sebagai karyawan tetap. Manajemen juga harus mempunyai komitmen yang kuat dalam hal penyelenggaraan pelatihan dengan tetap memperhatikan aspek-aspek emotional intelligence, self-efficacy dan hardiness sehingga program pelatihan yang telah dirancang dapat dilaksanakan sepenuhnya.

\section{Ucapan Terima Kasih (Acknowledgement)}

Ucapan terima kasih juga penulis sampaikan kepada Bapak Abdur Rahman Irsyadi dan Bapak Abdul Rahman Harun selaku atasan yang telah memberikan keleluasaan dalam mengakses data dan informasi terkait penyusunan penelitian ini.

\section{REFERENSI}

Alfred, K.D., \& Smith, T.W. (1989). The hardy personality: Cognitive and physiological responses to evaluative threat. Journal of Personality and Social Psychology, 56, 2, 257266.

Bandura, A. (1977). Self-Efficacy: Toward a unifying theory of behavioral change. Psychological Review, 84, 191-215.

Bandura, A (1997). Self-Efficacy, The exercise of control. New York: W.H Freeman and Company.

Bar-On, R. (2000). Emotional and Social intelligence insights: from he emotional quotient inventory. In R. Bar-On \& J.D Parker (Eds.). The handbook of emotional intelligence: Theory, development, assessment, and application at home, school, and in the workplace (pp.363-388). San Fransisco, CA: Jossey-Bass.

Cole, M.S., \& Field, H.S (2004). Student learning motivation and psychological hardiness: interactive effects on students' reaction to a management class. Academy of Management Learning and Education, 3, 1, 64-85.

Dogaheh, E.R., Khaledian, M. \& Arya, A.R.M. (2013). The relationship of psychological hardiness with emotional intelligence and workaholism. Research Papers, 1, 4, 211-217.

Goleman, D. (1995). Emotional Intelligence: The theory in practice. New York: Basic Book.

Kobasa (1979). Stressful life events, personality and health. Journal of Personality and Social Psychology, 37, 1,1-11.

Maddi, S.R (2002). The story of hardiness: twenty tears of theorizing, research, and practice. Consulting Psychology Journal: Practice and Research, 54 (3), 175-185. 
Maddi, S.R. (2006). Hardiness: The courage to grow from stress. The Journal of Positive Psychology, 1 (3), 160-168.

Mayer, J. D., Salovey, P., \& Caruso. D. R. (2004). Emotional intelligence: Theory, findings, and implications. Psychological Inquiry, 15 (3), 197-215.

Orr, E. \& Westman, M. (1990). Does hardiness moderates stress, and how: A review. New York: Springer.

Salovey, P., Bedell, B., Detweiler, J., \& Mayer, J. (1999). Coping Intelligently: Emotional intelligence and the coping process. In C. R. Snyder (Ed.), Coping: The psychology of what works (pp.141-164). New York: Oxford University Press.

Schutte, N.S., Malouff, J. M., Hall, L.E., Haggerty, D. J., Copper, J. T., Golden, C. J., \& Dornheim, L. (1998). Development and validation of measure of emotional intelligence. Personality and individual Difference, 25, 167-177.

Shekarey, A., Moghadam, A. J., Amiri, F., \& Rostami, M. S. (2010). The relation of self-efficacy and hardiness with the education progression among the sophomore girl students in high school in Aleshtar city. Procedia Social and BehavioralSsciences, 5, 1905-1910. 